\title{
VIGNETTE
}

\section{The Ropewalker}

CHRYSSA SGOURIDOU

University of Exeter (UK)

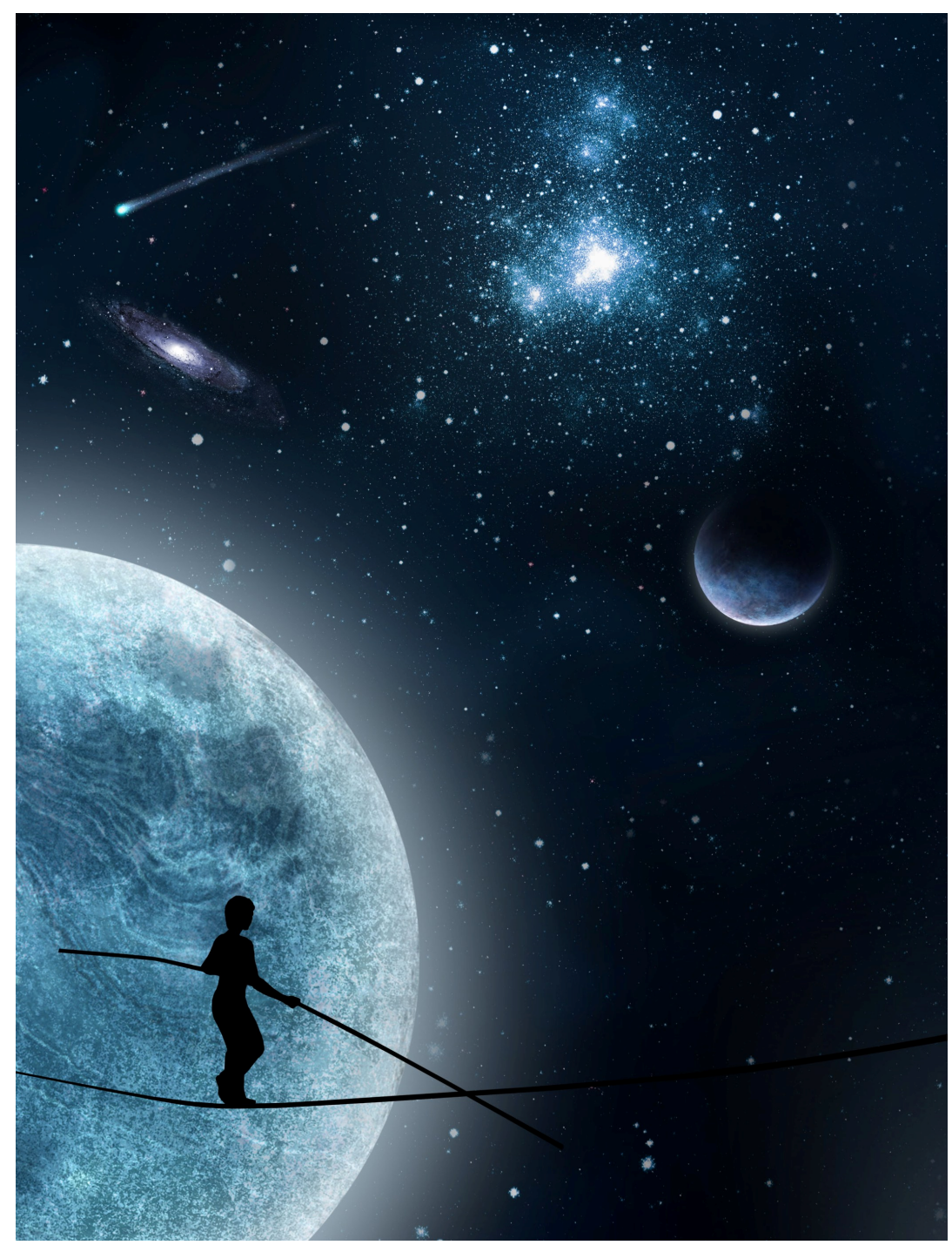

Complicity: An International Journal of Complexity and Education

Volume 7 (2010), Number $2 \bullet p p$. 114-115 


\title{
Acknowledgements
}

My sincere thanks to Stefanos Michaelides for designing the background image of the universe; and to Eleni Sgouridou and George Tsometzidis for their patient help at different stages of the process. Without their invaluable technical support the completion of the vignette would not have been possible. My sincerest gratitude to Suzanne Azer for her solid ethical support. I am forever grateful to the French high wire artist, Philippe Petit and the French writer Jean Genet, whose mind-blowing work inspired the piece.

\begin{abstract}
About the Author
Chryssa Sgouridou is a PhD student in the Graduate School of Education at the University of Exeter (UK). Currently researching in the area of democracy and drama education, she is particularly inspired by post-structural thought. Her research interests include identity, existence (and the phenomenon of life), interaction, inclusion and freedom, ethics, politics, artistic and socio-political activism. She is a scholar of the Alexander S. Onassis Public Benefit Foundation. Her email address is chryssasgouridou@gmail.com.
\end{abstract}

(c) Copyright 2010. The author, CHRYSSA SGOURIDOU, assigns to the University of Alberta and other educational and non-profit institutions a non-exclusive license to use this document for personal use and in courses of instruction provided that the article is used in full and this copyright statement is reproduced. The author also grants a non-exclusive license to the University of Alberta to publish this document in full on the World Wide Web, and for the document to be published on mirrors on the World Wide Web. Any other usage is prohibited without the express permission of the author. 